\title{
Angiopoietin 2 regulates the transformation and integrity of lymphatic endothelial cell junctions
}

\author{
Wei Zheng, ${ }^{1,2}$ Harri Nurmi, ${ }^{1,2,11}$ Sila Appak, ${ }^{3,4,11}$ Amélie Sabine, ${ }^{5}$ Esther Bovay, ${ }^{5}$ Emilia A. Korhonen, ${ }^{2}$ \\ Fabrizio Orsenigo, ${ }^{6,7}$ Marja Lohela, ${ }^{8}$ Gabriela D'Amico, ${ }^{2}$ Tanja Holopainen, ${ }^{2}$ Ching Ching Leow, ${ }^{9}$ \\ Elisabetta Dejana, ${ }^{6,7}$ Tatiana V. Petrova, ${ }^{5,10}$ Hellmut G. Augustin, ${ }^{3,4}$ and Kari Alitalo ${ }^{1,2,12}$ \\ ${ }^{1}$ Wihuri Research Institute, ${ }^{2}$ Translational Cancer Biology Program, University of Helsinki, Helsinki 00014, Finland; ${ }^{3}$ Division \\ of Vascular Oncology and Metastasis, German Cancer Research Center Heidelberg, Heidelberg 69120, Germany; ${ }^{4}$ Department of \\ Vascular Biology and Tumor Angiogenesis, Heidelberg University, Mannheim 68167, Germany; ${ }^{5}$ Department of Oncology, Centre \\ Hospitalier Universitaire Vaudois, University of Lausanne, Epalinges CH-1066, Switzerland; ${ }^{6}$ FIRC Institute of Molecular Oncology, \\ Milan 20139, Italy; ${ }^{7}$ Department of Biotechnological and Biomolecular Sciences, University of Milan, Milan 20129, Italy; ${ }^{8}$ Biomedicum \\ Imaging Unit, Biomedicum Helsinki, University of Helsinki, Helsinki 00014, Finland; ${ }^{9}$ MedImmune, Gaithersburg, Maryland 20878, \\ USA; $^{10}$ Swiss Institute for Cancer Research, École Polytechnique Fédérale de Lausanne, Lausanne CH-1066, Switzerland
}

Primitive lymphatic vessels are remodeled into functionally specialized initial and collecting lymphatics during development. Lymphatic endothelial cell (LEC) junctions in initial lymphatics transform from a zipper-like to a button-like pattern during collecting vessel development, but what regulates this process is largely unknown. Angiopoietin 2 (Ang2) deficiency leads to abnormal lymphatic vessels. Here we found that an ANG2-blocking antibody inhibited embryonic lymphangiogenesis, whereas endothelium-specific ANG2 overexpression induced lymphatic hyperplasia. ANG2 inhibition blocked VE-cadherin phosphorylation at tyrosine residue 685 and the concomitant formation of button-like junctions in initial lymphatics. The defective junctions were associated with impaired lymph uptake. In collecting lymphatics, adherens junctions were disrupted, and the vessels leaked upon ANG2 blockade or gene deletion. ANG2 inhibition also suppressed the onset of lymphatic valve formation and subsequent valve maturation. These data identify ANG2 as the first essential regulator of the functionally important interendothelial cell-cell junctions that form during lymphatic development.

[Keywords: angiopoietin 2; lymphatic; VE-cadherin; junction]

Supplemental material is available for this article.

Received January 7, 2014; revised version accepted June 9, 2014.

Lymphatic vessels form a unidirectional vascular drainage system that plays important roles in fluid homeostasis, immune responses, and fat absorption (Tammela and Alitalo 2010). Malfunction of lymphatic vessels occurs in many pathological conditions, such as cancer, lymphedema, and inflammatory diseases (Alitalo 2011; Schulte-Merker et al. 2011). The mature lymphatic vascular tree has a hierarchical structure, with different components performing distinct functions. Blind-ended initial lymphatics are the entry sites for fluid, macromolecules, and leukocytes. Collecting lymphatics conduct lymph from initial lymphatics to lymph nodes, where immune responses are activated, and the fluid is returned to venous circulation. Collecting lymphatics are surrounded by smooth muscle

\footnotetext{
${ }^{11}$ These authors contributed equally to this work.

${ }^{12}$ Corresponding author

E-mail kari.alitalo@helsinki.fi

Article is online at http://www.genesdev.org/cgi/doi/10.1101/gad.237677.114.
}

cells (SMCs) and contain intraluminal valves, which facilitate lymph drainage and prevent lymph backflow, respectively. Malformation of these structures can cause diseases. For example, defective valve formation and ectopic SMC association with initial lymphatics lead to lymphedema distichiasis in FOXC2 mutant patients and Foxc2 ${ }^{-/-}$mice (Petrova et al. 2004).

Both initial lymphatics and collecting lymphatics are lined by a single layer of lymphatic endothelial cells (LECs), which are derived from venous endothelial cells (ECs) during embryonic development (Yang and Oliver 2014). Developing LECs first form primitive intermediate structures, which then go through a series of expansion

(C) 2014 Zheng et al. This article is distributed exclusively by Cold Spring Harbor Laboratory Press for the first six months after the full-issue publication date (see http://genesdev.cshlp.org/site/misc/terms.xhtml). After six months, it is available under a Creative Commons License (Attribution-NonCommercial 4.0 International), as described at http:// creativecommons.org/licenses/by-nc/4.0/. 
and remodeling processes and finally give rise to the mature lymphatic vascular system (Koltowska et al. 2013). During this process, primitive LECs are destined to form different functional units of the lymphatic system, such as the initial and the collecting lymphatics. The LECs that constitute these two lymphatic compartments differ in a number of aspects, including differential expression of a set of genes (Norrmén et al. 2009). Among the differences, a prominent distinction is the pattern of cell-cell junctions.

Initial lymphatics have button-like junctions (buttons), whereas collecting lymphatics have zipper-like junctions (zippers) (Baluk et al. 2007). These specialized junctions are considered important for the entrance of lymph through the gaps between the buttons in initial lymphatics and for preventing leakage from collecting lymphatics (Baluk et al. 2007). A recent study showed that developing initial lymphatics in mice first have zippers, which start to transform to buttons around birth, and only buttons are visible in initial lymphatics at $10 \mathrm{wk}$ of age in mice (Yao et al. 2012). However, little is known about the regulation of this transformation. Moreover, it remains unclear whether primitive collecting lymphatics also have zippers initially and, if so, how they are maintained.

Lymphangiogenesis, the growth of lymphatic vessels, is controlled by a number of growth factors, including those of the vascular endothelial growth factor (VEGF) family and the angiopoietin/TIE family (Zheng et al. 2014). Many of these factors also regulate angiogenesis. Angiopoietin 1 (ANG1) and its receptor, TIE2, are critical for blood vessel formation and vessel remodeling during embryonic development, and deficiency of either one results in embryonic lethality (Dumont et al. 1994; Sato et al. 1995; Suri et al. 1996; Patan 1998; Jeansson et al. 2011). ANG2, another growth factor of the family, was first recognized as a natural antagonist of ANG1/TIE2 signaling, since transgenic overexpression of Ang2 in mouse embryos led to a lethal phenotype similar to that of Ang1delected mice (Maisonpierre 1997). However, the effects of ANG2 on blood vessels are context-dependent (Augustin et al. 2009). In lymphatic vessels, ANG2 appears to be only a TIE2 agonist (Gale et al. 2002; Dellinger et al. 2008). Ang2-null mice suffer from insufficient growth of lymphatic vessels, which have abnormal morphologies and remodeling defects (Gale et al. 2002; Dellinger et al. 2008). ANG2 has been suggested to destabilize blood vessels and is associated with increased vascular leakiness in cancer and sepsis (van der Heijden et al. 2009; Huang et al. 2010; Holopainen et al. 2012b; Ziegler et al. 2013). However, how ANG2 affects EC junctions in blood and lymphatic vessels is poorly understood.

In this study, we used an ANG2-blocking antibody and genetic approaches in mice to test whether ANG2 regulates specialization of the distinct patterns of LEC junctions and analyzed the role of ANG2 in valve formation and SMC recruitment. Addressing these questions will help to understand the specialization and maturation of functional initial and collecting lymphatics.

\section{Results}

ANG2 regulates lymphangiogenic processes during embryonic development

To study the function of ANG2 in lymphatic development, we used a monoclonal antibody that specifically blocks the binding of ANG2 to TIE2 (Mazzieri et al. 2011; Leow et al. 2012). The antibody was given every other day to pregnant female mice starting from embryonic day 12.5 (E12.5). Analysis of the embryos at E18.5 revealed body swelling and hemorrhages in the toes and tails (Supplemental Fig. S1A), but these embryos survived, and the blood vessels in the skin and mesentery appeared normal (Supplemental Figs. S1B,C, 6G,H). In contrast, the cutaneous lymphatic vessels showed a number of defects (Fig. 1A-I). Lymphatic vessel development toward the linea alba in the ventral midline was severely reduced (Fig. 1A,E), and the vessels at the sprouting front lacked filopodia (Fig. 1B,F). Lymphatic vessel density, circumferential expansion of the vessels, and EC proliferation were also significantly decreased (Fig. $1 \mathrm{C}, \mathrm{D}, \mathrm{G}-\mathrm{I})$.

To investigate whether Ang2 overexpression would produce effects opposite to those of ANG2 blockade, we used an inducible genetic mouse model, the VE-cadherintTA; Tet-OS-Ang2 double-transgenic (DTG) mice, to overexpress mouse Ang2 specifically in the endothelium (Holopainen et al. 2012b). The DTG embryos died at E10.5 when the transgene was not suppressed by tetracycline (Supplemental Fig. S1D), similar to as reported for embryos constitutively overexpressing Ang2 (Maisonpierre 1997). When Ang2 overexpression was induced by stopping tetracycline administration at E10.5, the DTG embryos were indistinguishable in appearance from their wild-type littermates at E18.5 (data not shown), and the blood vessels in the skin appeared normal (Supplemental Fig. S1E-G). Although Ang2 overexpression did not increase lymphatic vessel density, it increased LEC proliferation and the vessel caliber (Fig. 1J,L; Supplemental Fig. S1H,I).

Since VEGF-C is a major lymphangiogenic factor that activates its receptor, VEGF receptor 3 (VEGFR3), on the surface of LECs (Zheng et al. 2014), we asked whether Ang2 overexpression could rescue some of the phenotypes resulting from VEGFR3 blockade. Inhibition of VEGFR3 signaling with a specific blocking antibody (Pytowski et al. 2005) injected from E12.5 on led to an almost complete absence of lymphatic vessels in the ventral skin and mesentery in E18.5 embryos regardless of whether they were wild type or Ang2-overexpressing (data not shown). When the VEGFR3-blocking antibody was injected at E14.5 into wild-type females and the ventral skin of the embryos was analyzed at E18.5, the lymphatic vessel density and caliber were reduced (Fig. 1J-L). ANG2 overexpression did not rescue the reduced vessel density but restored the number of LECs per vessel length and the vessel caliber to levels comparable with those of the control antibody-treated wild-type embryos (Fig. 1J-L). These data suggest that ANG2 can partially rescue the lack of VEGFC/VEGFR3 signaling, 


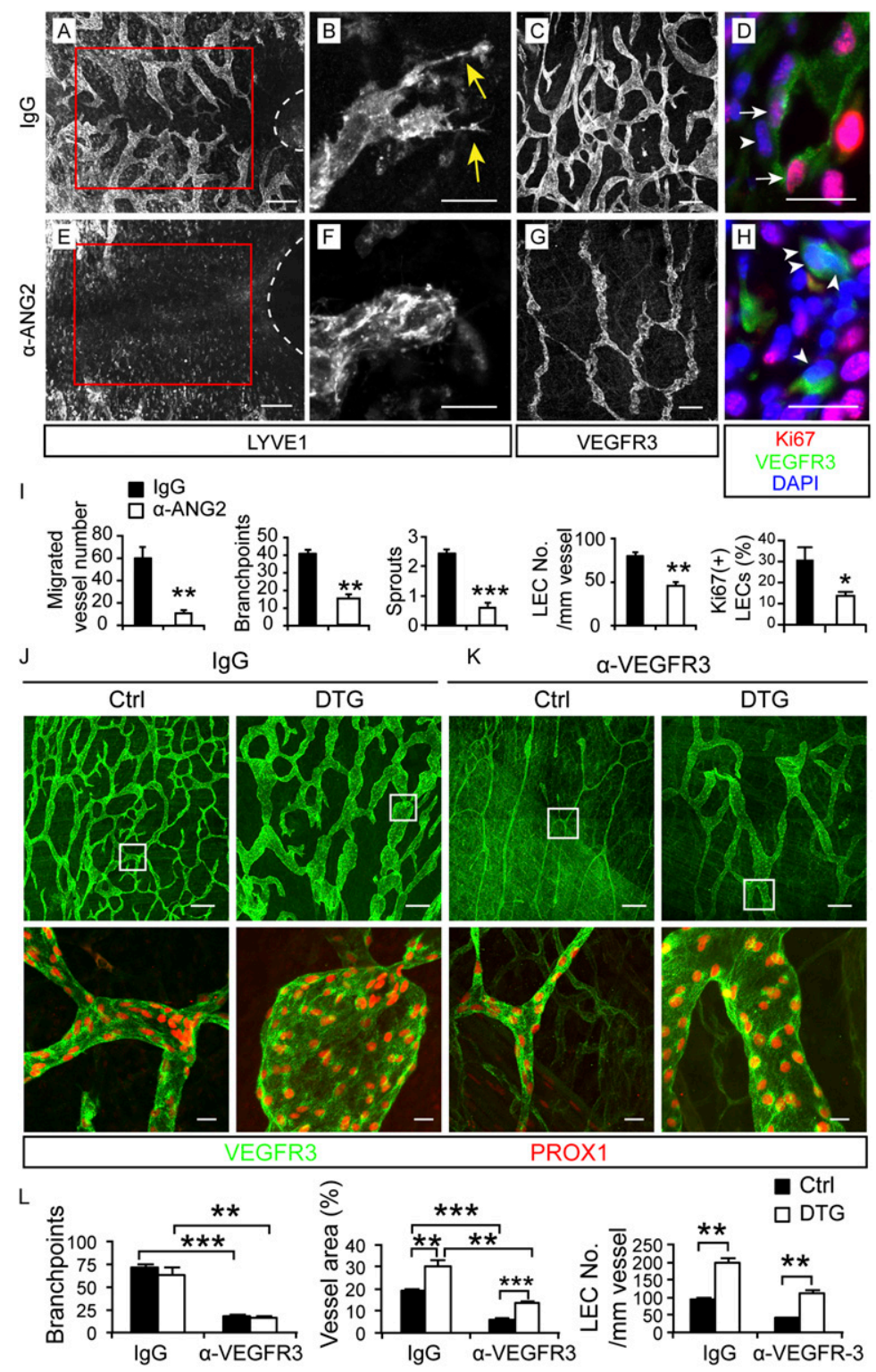

Figure 1. ANG2 regulates lymphangiogenesis during embryonic development. $(A-H)$ Pregnant females were injected intraperitoneally (i.p.) with $30 \mathrm{mg} / \mathrm{kg}$ ANG2blocking antibody or a control antibody at E12.5, E14.5, and E16.5, and the ventral skin of embryos was analyzed at E18.5 by immunofluorescence for LYVE1, VEGFR3, Ki67, and PROX1, as indicated. Dashed lines indicate the umbilicus. Vessels inside the red squares are quantified in I. (Yellow arrows) Sprouts; (white arrows) Ki67 ${ }^{+}$LECs; (arrowheads) Ki67 ${ }^{-}$LECs. Bars: $A, E, 200 \mu \mathrm{m} ; B, C, F, G, 20 \mu \mathrm{m} ; D, H, 10 \mu \mathrm{m}$. (I) Quantification of the migration, branch points, and sprouts; the number of LECs per 1-mm vessel; and the percentage of Ki67 ${ }^{+}$LECs out of all LECs. $N=4-5$. $(J-L)$ The mothers of VE-cadherin-tTA; TetO-Ang2 embryos were provided with tetracycline water until E10.5, and the ventral skin of the embryos was analyzed at E18.5. The anti-VEGFR3 antibody $(30 \mathrm{mg} / \mathrm{kg})$ was injected i.p. at E14.5 and E16.5. (DTG) Double transgenic for VEcadherin-tTA and TetO-Ang2; (Ctrl) control embryos (wild type [WT] or single transgenic). $N=4-7$. Boxed regions are magnified in the bottom panel. Bars: top panel, $200 \mu \mathrm{m}$; bottom panel, $20 \mu \mathrm{m}$. All values are mean \pm SEM. $\left(^{\star}\right) P<0.05 ;\left(^{\star \star}\right) P<0.01 ;\left(^{\star \star \star}\right) P<0.001$.

which further corroborates its role as a lymphangiogenic factor.

\section{ANG2 is required for maturation of endothelial cell-cell junctions in initial lymphatics}

LEC junctions undergo a gradual transformation from zippers to buttons around birth in the initial lymphatics of the trachea and diaphragm (Yao et al. 2012). We found that the VE-cadherin-positive adherens junctions in the dermal initial lymphatics also transformed from zippers to buttons, although at an earlier time point, around E16.5 (Supplemental Fig. S2A, arrowheads and arrows). To understand whether ANG2 regulates this transformation process, we treated pregnant females with the ANG2blocking antibody starting from E12.5, before the transformation occurs, and analyzed the embryos at E18.5. At the sprouting vessel front, junctions in the IgG-treated lymphatics were zippers (Fig. 2A,B), consistent with the junctional pattern at the sprouting front reported elsewhere (Baluk et al. 2007; Yao et al. 2012), and ANG2 blockade did not affect this pattern (Fig. 2C,D). In the IgGtreated initial lymphatics behind the sprouts, the LEC shape was less elongated, and the junctions were clearly button-like (Fig. 2E,F). Strikingly, ANG2 inhibition suppressed essentially all button formation (Fig. 2G,H).

Dexamethasone has been reported to promote precocious button formation (Yao et al. 2012). We asked whether such promotion is sufficient for the transformation without ANG2 activity. Whereas dexamethasone treatment of pregnant females from E12.5 to E18.5 resulted in prominent button formation, including in the sprouting vessel front (Fig. 2I,J,M,N), anti-ANG2 treatment for the same period inhibited the button formation also in the dexamethasonetreated vessels (Fig. 2K,L,O,P). Thus, ANG2 is indispensable for the zipper-to-button remodeling of LEC junctions. 


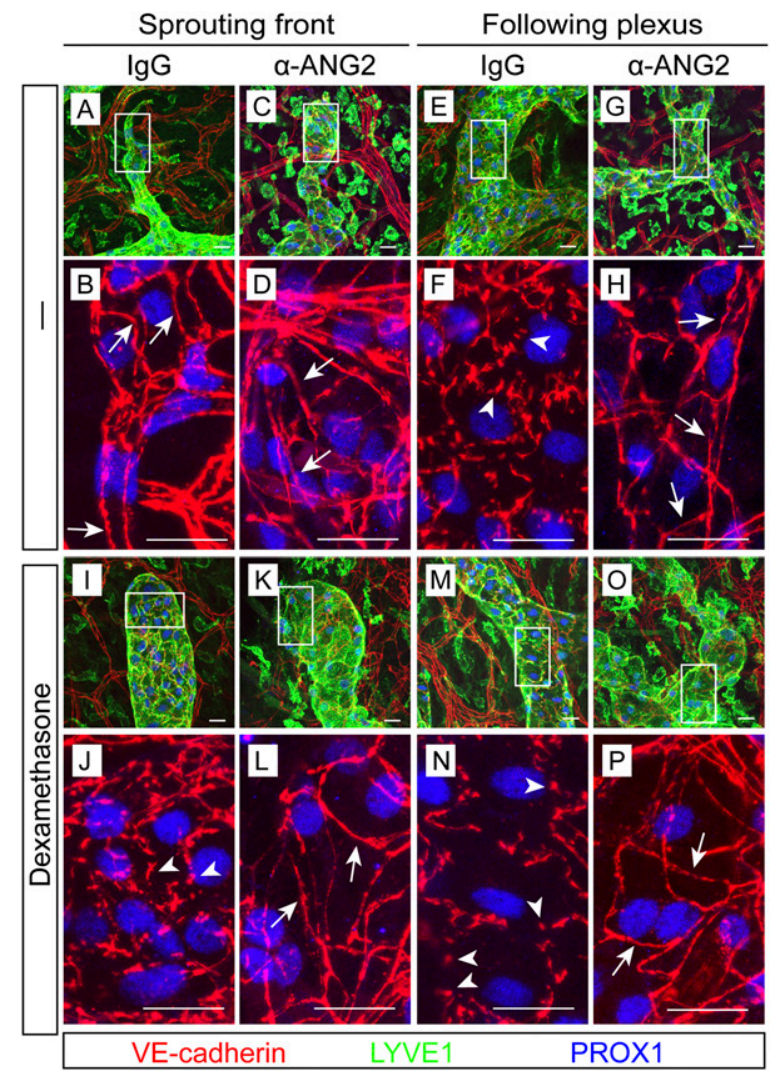

Figure 2. ANG2-inhibited embryos fail to form button-like junctions in initial lymphatics. $(A-H)$ Pregnant females were treated with the ANG2-blocking or a control antibody at E12.5, E14.5, and E16.5, and the ventral skin of embryos was analyzed at E18.5. $N=15-16$ from five independent experiments. $(I-P)$ Females were treated with the indicated antibodies as above together with $1 \mathrm{mg} / \mathrm{kg}$ dexamethasone. $N=4$. Boxed regions in $A-G$ and $I-O$ are magnified in the panels below them. (Arrows) Zippers; (arrowheads) buttons.

When the LEC junctions of initial lymphatics had already transformed into buttons after birth, the ANG2blocking antibody could not revert the buttons back to zippers (Supplemental Fig. S2B), suggesting that ANG2 is needed for the junction remodeling but dispensable for the maintenance of the already remodeled junctions. In addition, overexpression of ANG2 did not seem to affect LEC junctions (Supplemental Fig. S2C).

\section{Genetic deletion of Ang2 suppresses junctional maturation in initial lymphatics}

To validate the results obtained with the ANG2-blocking antibody, we also analyzed the initial lymphatics in Ang2 gene-deleted (-/-) mice (Gale et al. 2002; Fiedler et al. 2006). In agreement with the results of the blocking antibody experiment, the zipper-to-button junctional transformation was also reduced in the diaphragm of $A n g 2^{-/-}$ neonates at postnatal day 5 (P5) (Fig. 3A). This suggests that the requirement of ANG2 for the maturation of LEC junctions in initial lymphatics is not restricted to the skin but is more general.
We next checked whether the defective junctions persist in adult mice. In 10-wk-old wild-type mice, lymphatic vessels have become quiescent without any sprouts in the initial lymphatics, including the sprouting vessel front, where LEC junctions are mostly buttons (Yao et al. 2012). In our analysis of 8 -wk-old wild-type mice, $64 \%$ of the junctions were made of mature buttons, whereas in the Ang2-deleted littermates, mature buttons made up only $17 \%$ of the junctions (Fig. 3B-K; Supplemental Fig. S2D-F). Concurrent with the defective junctions, distribution of the lymphatic endothelial hyaluronan receptor LYVE1 was also abnormal: It was diffuse in the LECs of the zipper pattern or concentrated at the cell-cell borders at the transforming stage, in contrast to the high levels in the LEC flaps of mature initial lymphatics (Fig. 3C,F,J, arrows, arrowheads, and empty arrows, respectively). Although compensatory mechanisms may thus exist to induce partial transformation of the junctions eventually, the role of Ang2 in this process is substantial.

\section{Lymphatic uptake is impaired in embryos upon ANG2 inhibition}

Since the anti-ANG2-treated embryos appeared swollen (Supplemental Fig. S1A) and Ang $2^{-/-}$mice develop peripheral lymphedema (Gale et al. 2002), we tested whether the defective junctions would compromise lymphatic uptake. A fluorescent tracer injected into the periorbital dermis and footpads was readily drained by the lymphatic vessels in the IgG-treated embryos (Fig. 4A-C) but not in any of the 11 anti-ANG2-treated embryos analyzed at E19.5 (Fig. 4D-F). These results suggest that the failure to transform into button-like junctions in initial lymphatics contributes to impaired lymph uptake.

\section{ANG2 blockade inhibits VE-cadherin phosphorylation at Y685 while arresting the transformation into button- like junctions}

Phosphorylation of the tyrosine residue 685 (P-Y685) of VE-cadherin has been implicated in VE-cadherin destabilization and increased vascular permeability (Dejana et al. 2008; Vestweber et al. 2009; Orsenigo et al. 2012). To determine whether VE-cadherin phosphorylation at this site is regulated by ANG2 in initial lymphatics, we stained the anti-ANG2- and IgG-treated embryos with an antibody that specifically recognizes VE-cadherin P-Y685 (Orsenigo et al. 2012). Most of the VE-cadherin in both LEC zippers and buttons appeared phosphorylated at Y685 in the IgG-treated skin (Fig. 5A-C,G-I,M; Supplemental Fig. S3A). In striking contrast, little P-Y685 was detected in VEcadherin in the lymphatic vessels of the anti-ANG2-treated embryos (Fig. 5D-F,J-M; Supplemental Fig. S3A), and the VE-cadherin P-Y685-negative junctions failed to undergo zipper-to-button transformation at the same time (Fig. 5K).

In adult mice, VE-cadherin is phosphorylated at Y685 in veins but not in arteries (Orsenigo et al. 2012). We observed that arterial VE-cadherin was also phosphorylated at Y685 during embryonic development (Supplemental Fig. S3A,B). However, ANG2 blockade did not alter VE-cadherin P-Y685 in the arteries, veins, or blood 


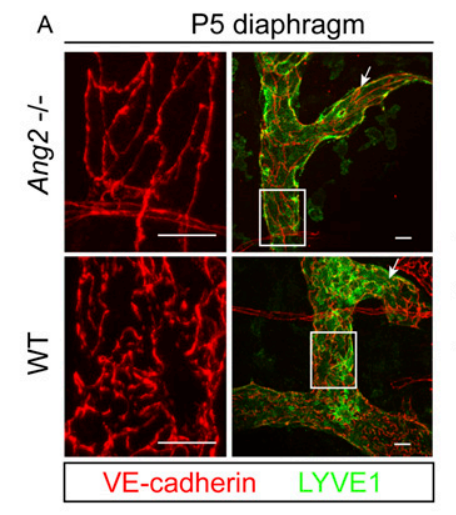

$\mathrm{K}$
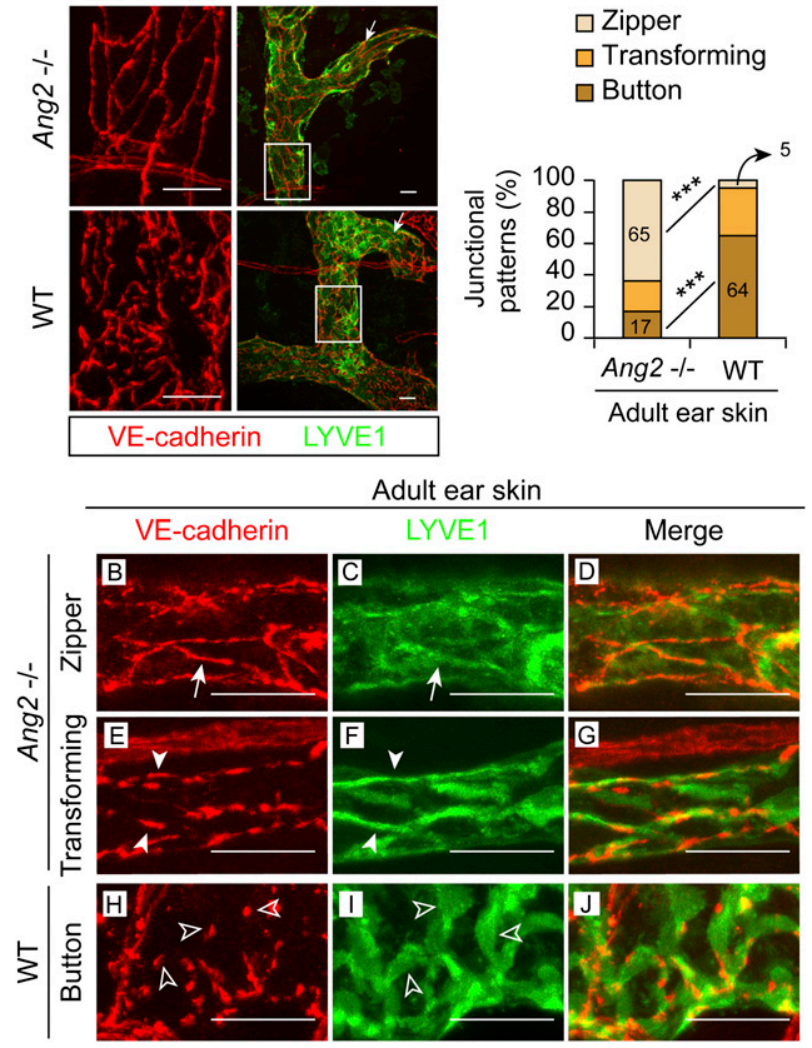

Figure 3. Ang2 gene deletion impairs the zipper-to-button junctional transformation in initial lymphatics. $(A)$ The diaphragms of Ang2 ${ }^{-1-}$ or wild-type (WT) P5 pups were whole-mount-stained. (Arrows) Sprouting front. Boxed regions are magnified in the left panel. $N=4-5$. $(B-K)$ The ear skin of 8 -wk-old Ang2 $2^{-1-}$ mice $(B-G)$ and their wild-type littermates $(H-I)$ was whole-mountstained. (Arrows) Zippers; (arrowheads) transforming junctions; (empty arrowheads) buttons. (K) Quantification of 36-43 initial lymphatics from four mice of each genotype, analyzed for their junctional patterns. $\left(^{\star \star \star}\right) P<0.001$. Bars, $20 \mu \mathrm{m}$ in all.

capillaries (Supplemental Fig. S3A [arrows], B), which indicates that ANG2 regulates Y685 phosphorylation only in embryonic lymphatic vessels.

\section{Inhibition of ANG2 results in abnormal collecting vessel structure in embryos}

To extend the analysis of ANG2 functions to collecting lymphatics, we stained mesenteric lymphatic vessels for VE-cadherin at different developmental stages. The LEC junctions at E14.5-E18.5 were zippers, as in mature collecting lymphatics (Supplemental Fig. S4A). The IgGtreated collecting lymphatics, when analyzed at E18.5, were stretched and multicellular, with an elongated EC shape (Supplemental Fig. S4B-E). In contrast, the antiANG2-treated collecting lymphatics were either immature, with very few LECs across the vessel diameter (Supplemental Fig. S4F-I,N), or loose and ragged, with a rounded cell shape mimicking that of the LECs in initial lymphatics (Supplemental Fig. S4J-M). In addition, few lymphatic valves were found (Supplemental Fig. S4E,I,M), consistent with the findings in Ang $2^{-/-}$mice (Dellinger et al. 2008). The integrity of the adherens (zipper) junctions and their phosphorylation at Y685, however, appeared unaltered at this stage (Supplemental Fig. S4B,C,F,G,J,K). Neither dexamethasone nor ANG2 overexpression changed the pattern of junctions in the mesenteric collecting lymphatics (Supplemental Fig. S4O,P).

\section{ANG2 maintains the integrity of the collecting lymphatics during postnatal development}

We then examined whether ANG2 regulates LEC junctions in collecting lymphatics during postnatal development. Similar to constitutive Ang2 deletion (Gale et al. 2002; Dellinger et al. 2008), postnatal ANG2 inhibition with the blocking antibody also induced chylous ascites in nine out of 32 P5 pups (Supplemental Fig. S5A), and essentially all of the anti-ANG2-treated neonates showed chyle leakage into the mesentery (Fig. 6A-D). Furthermore, the LEC morphology in the collecting lymphatics became rounded, and the junctions were disrupted, with a jagged shape and breaks of zipper continuity (Fig. 6E-H).

To corroborate these data, we also analyzed the LEC junctions in the collecting lymphatics of $A n g 2^{-1-}$ mice. In the mesentery of $A n g 2^{-l-}$ pups, the junctions were similarly disrupted (Fig. 6I; Supplemental Fig. S5B). In the ear skin of 8-wk-old mice, the junctions in the collecting lymphatics were also disrupted; in some cases, they even resembled the button pattern (Fig. 6J-O; Supplemental Fig. S5C-E). Interestingly, these abnormal collecting lymphatics did not down-regulate LYVE1 (Fig. 6M-O), which indicates that their maturation was impaired. In line with the loss of integrity of the adherens junctions, FITCdextran leaked out from the collecting lymphatics in the

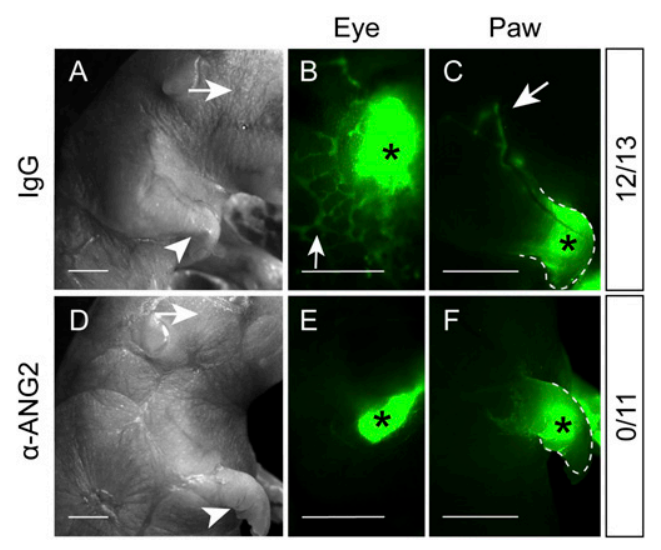

Figure 4. Defective lymph uptake in anti-ANG2-treated embryos. Pregnant females were treated with IgG $(A-C)$ or the ANG2-blocking antibody $(D-F)$ at E12.5, E14.5, and E17.5. At E19.5, the embryos were injected with FITC-Dextran in the periorbital dermis (arrows in $A, D$ ) or forelimb footpad (arrowheads in $A, D)$ and imaged to check the tracer uptake by lymphatic vessels. $(B, C)$ Arrows indicate the tracer drained by the lymphatic vessels in the IgG-treated embryos (12 of 13). $(E, F)$ No tracer uptake was observed in the anti-ANG2treated embryos $(N=11) .\left(^{\star}\right)$ Injection sites. Bars: $A, D, 2 \mathrm{~mm}$; $B, C, E, F, 1 \mathrm{~mm}$. 


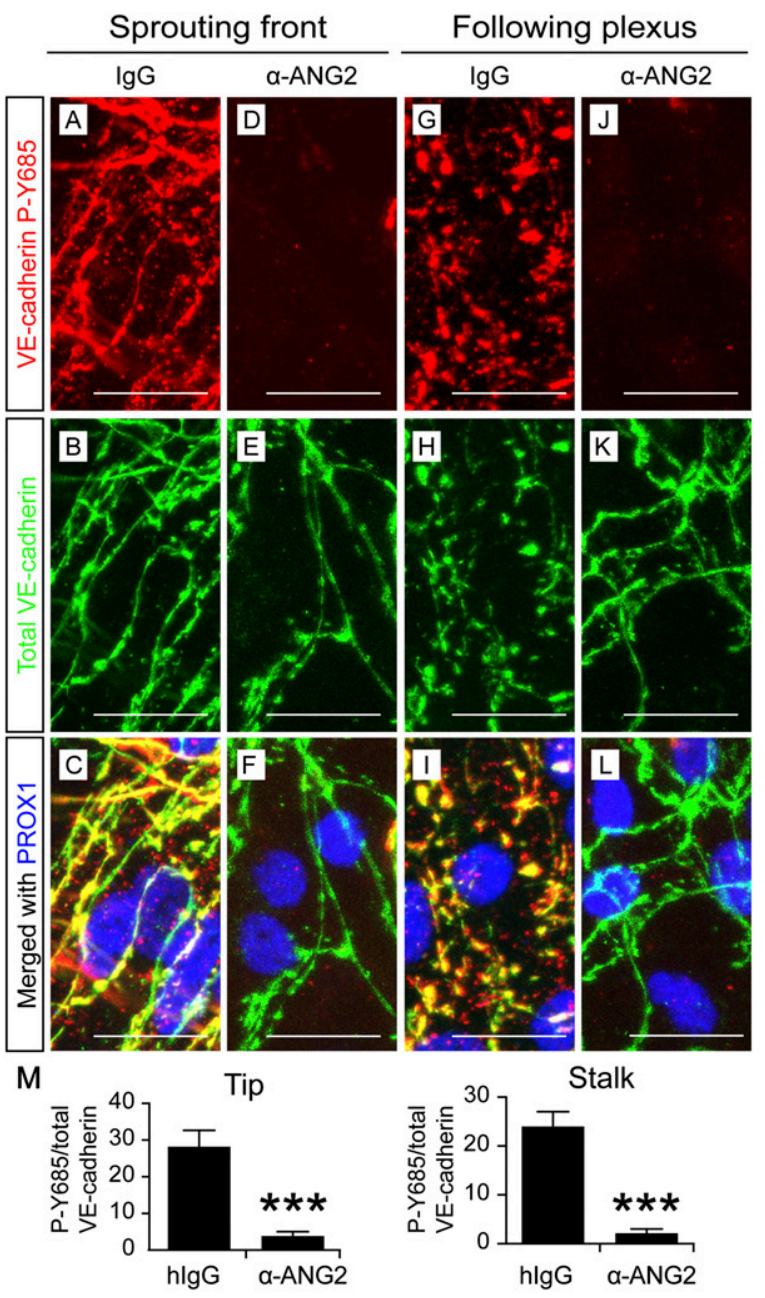

Figure 5. ANG2 is required for VE-cadherin Y685 phosphorylation in developing initial lymphatics. Pregnant females were treated with the control antibody $(A-C, G-I)$ or the ANG2blocking antibody $(D-F, J-L)$ at E12.5, E14.5, and E16.5, and the ventral skin from the embryos was analyzed at E18.5. Bars, 20 $\mu \mathrm{m}$. (M) Quantification of the intensities of VE-cadherin P-Y685positive pixels out of those of the total VE-cadherin-positive pixels. $N=6$, pooled from two independent experiments with consistent results. $\left(^{\star \star \star}\right) P<0.001$.

central parts of the $A n g 2^{-/-}$ears after it was injected into the ear tips and collected by the surrounding initial lymphatics (Fig. 6P). Furthermore, Evans blue dye injected intradermally into the footpads of $A n g 2^{-/-}$mice was drained less efficiently via the lymphatic system into the blood circulation (Fig. 6Q). Given that the EC junctions are defective in both the initial lymphatics and collecting lymphatics, the compromised draining capacity may result from a combination of defects in the uptake by the initial lymphatics and leakage by the collecting lymphatics.

\section{ANG2 is required for valve formation and maturation}

Lymphatic valves start to form at about E16 (Norrmén et al. 2009). The FOXC2 transcription factor is essential for valve formation, in cooperation with PROX1, a transcription factor critical for the commitment to LEC identity (Wigle and Oliver 1999; Petrova et al. 2004; Norrmén et al. 2009; Sabine et al. 2012). Since few valves form in the absence of ANG2 (Supplemental Fig. S4I,M; Dellinger et al. 2008), we examined whether ANG2 regulates valve formation via these two transcription factors. In the IgG-treated embryos at E18.5, FOXC2 and PROX1 were highly expressed at valves and were expressed at lower levels in lymphangions (segments between the valves) (Fig. 7A-C). When ANG2 was blocked starting from E12.5 and the embryos were analyzed at E18.5, FOXC2 was almost completely absent from the lymphatic vessels but not from the arteries (Fig. 7D-G). In contrast, PROX1 was uniformly and highly expressed in all LECs (Fig. 7E), resembling the pattern seen in the primitive collecting lymphatics at E14.5 (Supplemental Fig. S4A; Norrmén et al. 2009).

We next asked whether the suppression of FOXC2 was a direct effect of ANG2 blockade or secondary to the failed valve formation. FOXC2 expression in lymphatic vessels starts at E14.5, peaks at E15.5, and decreases in lymphangions at E17.5 (Norrmén et al. 2009). Thus, we examined whether ANG2 blockade inhibits FOXC2 expression at E15.5, when FOXC2 expression is highly and uniformly expressed by all LECs, just before valve formation. At this time point, although the LECs formed thin vessels containing only a few circumferentially organized cells, which indicated the inhibitory effect of ANG2 blockade, FOXC2 expression in the LECs was not altered (Supplemental Fig. S6A,B). These results indicate that ANG2 does not control the initiation of valve formation through FOXC2 expression. Instead, it seems to be required for the maintenance of FOXC2 expression in the prospective valve-forming LECs and for PROX1 downregulation in prospective lymphangion-forming LECs.

Subsequently, we analyzed the anti-ANG2-sensitive periods in lymphatic valve formation. Administration of the ANG2-blocking antibody starting at E14.5, right before valve formation, suppressed valve formation, similar to the treatment starting at E12.5 (Fig. $7 \mathrm{H}$ ). Thus, ANG2 likely has a direct effect on the initiation of valve formation. At E15-E16 during normal development, clusters of LECs that express abundant PROX1 and FOXC2 are selected to undergo valve morphogenesis (Bazigou et al. 2009; Norrmén et al. 2009; Sabine et al. 2012). These lymphatic valve-forming cells (LVCs) reorientate, migrate into the lumen, coalesce, form a ringshaped constriction, and then further extend valve leaflets in a V shape during E16-E18.5. We therefore blocked ANG2 starting at E15.5, when valve formation had just begun, and analyzed the valves at E18.5. This treatment did not block the occurrence of LVCs (Fig. 7IN). However, $53 \%$ of the LVCs failed to reorient and express integrin- $\alpha 9$ (a valve leaflet marker) (Fig. 7I-L,Q, termed stage 1 here; Bazigou et al. 2009), 32\% were arrested at the "ring-shape" stage (Fig. 7M-N,Q, stage 2), and only $15 \%$ matured to the V-shape stage (Fig. 7Q, stage 31 , in contrast to the $66 \%$ at stage 3 in the IgGtreated vessels (Fig. 7O-Q). On the other hand, the IgGtreated vessels had $<5 \%$ of stage 1 valves, compared with 


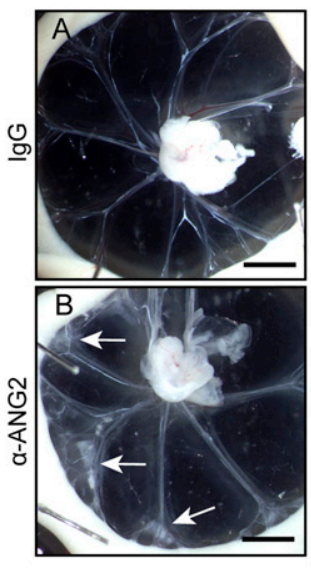

I

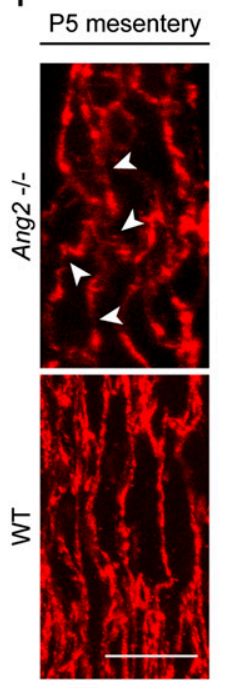

VE-cadherin

$\mathbf{P}$

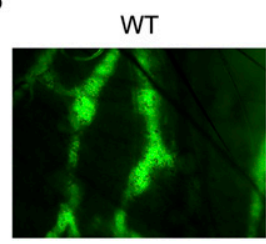

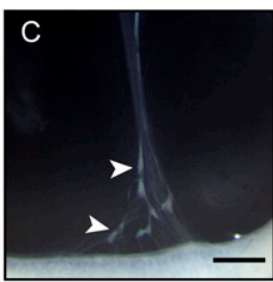
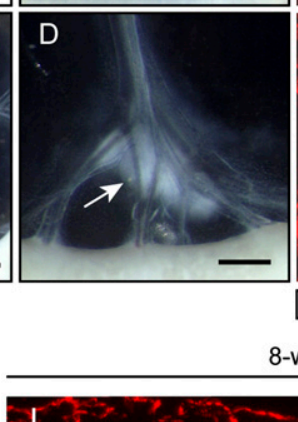
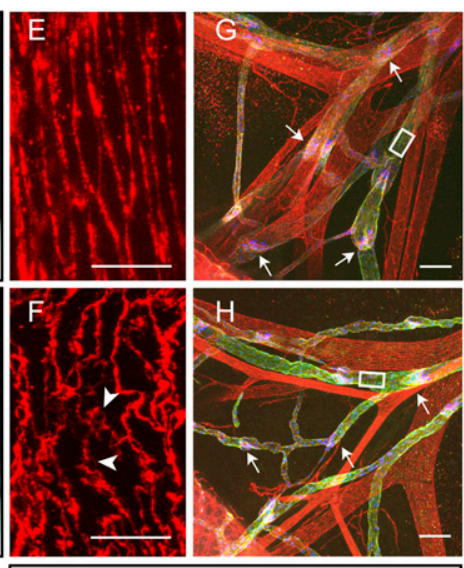

VE-cadherin

8-week old ear skin

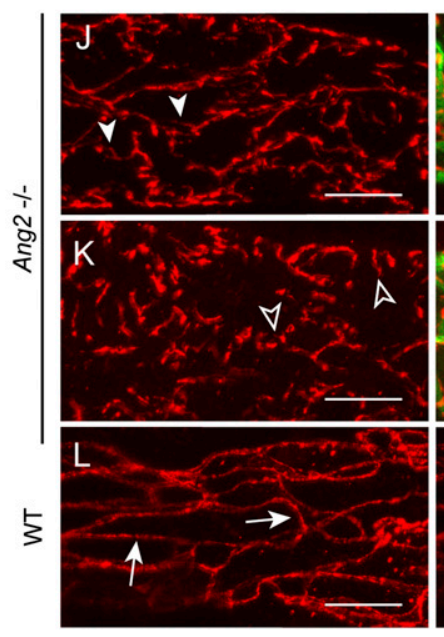

VE-cadherin

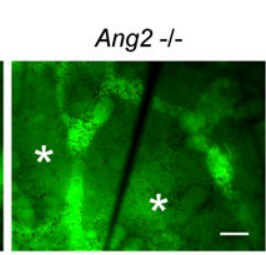

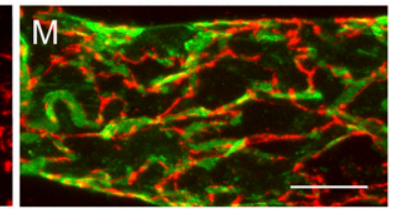
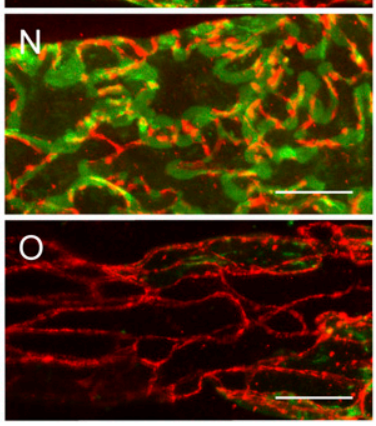

Merged with LYVE1

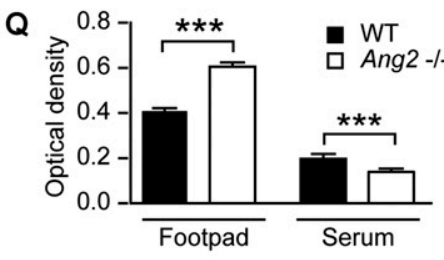

Figure 6. Disruption of adherens junctions in the collecting lymphatics of anti-ANG2-treated and $A n g 2^{-/-}$mice. $(A-D)$ Neonatal mice were injected with IgG or the anti-ANG2 antibody every other day starting from P0 and were analyzed at P5. (Arrows) Leak of chyle; (arrowheads) normal drainage of chyle by the collecting lymphatics. $(E-H)$ Whole-mount staining of the mesenteries in $A$ and $B$ for VEGFR3, VEcadherin, and PROX1. (Arrowheads) Disrupted interendothelial junctions; (arrows) valves. Boxed regions are magnified in $E$ and $F$. $N=7-9$, two independent experiments. (I) Whole-mount staining of the mesentery of $A n g 2^{-/-}$or wildtype (WT) pups at P5. (Arrowheads) Disrupted junctions. $(J-O)$ Collecting lymphatics in the ear skin of 8-wk-old Ang2-l- and wild-type littermate mice. (Arrows) Zippers; (arrowheads) disrupted junctions; (empty arrowheads) button junctions. $N=4-5$. $(P)$ FITC-Dextran lymphangiography of wild-type and $A n g 2^{-/-}$ears. Note the leaked tracer, as indicated by asterisks. $N=6$. (Q) Evans Blue content in the footpad and in blood circulation after intradermal injection in the lower limbs. $N=6 .\left(^{\star \star \star}\right) P<0.001$. Bars: $A, B, 2 \mathrm{~mm}$; $C, D, 0.5 \mathrm{~mm}$; E,F,I-O, $20 \mu \mathrm{m} ; G, H, P, 100 \mu \mathrm{m}$.

the $53 \%$ in the anti-ANG2-treated embryos (Fig. 7Q). After birth, inhibition of ANG2 did not affect the already formed valves (Fig. 6G,H, arrows). These data indicate that ANG2 is indispensable before and during valve morphogenesis but unnecessary when the valves have matured.

\section{ANG2 is important for proper SMC recruitment}

SMCs have been shown to ectopically cover initial lymphatics in the Ang2 $2^{-/-}$mice (Dellinger et al. 2008). This ectopic SMC coverage was also observed in the antiANG2-treated embryos in this study (Supplemental Fig. S7A-H). Since PDGFB is an important chemoattractant for mural cell recruitment to blood vessels (Betsholtz 2004), we considered the possibility that ANG2 inhibition leads to aberrant expression of PDGFB, which attracts SMCs to the initial lymphatics. To evaluate PDGFB expression, we used PDGFB-EGFP reporter mice (Claxton et al. 2008). Surprisingly, little PDGFB expression was detected in the initial lymphatics of anti-ANG2-treated embryos analyzed at E18.5 despite the SMC coating (Supplemental Fig. S7E-H). On the other hand, the collecting lymphatics in the antiANG2-treated embryos had only few SMCs even though PDGFB was expressed at levels apparently similar to those in the control embryos (Supplemental Fig. S7I-P). Thus, PDGFB does not seem to be responsible for the aberrant SMC recruitment induced by ANG2 inhibition.

\section{Discussion}

Unlike ANG1, ANG2 has been considered to be a contextdependent and somewhat elusive EC growth factor for 

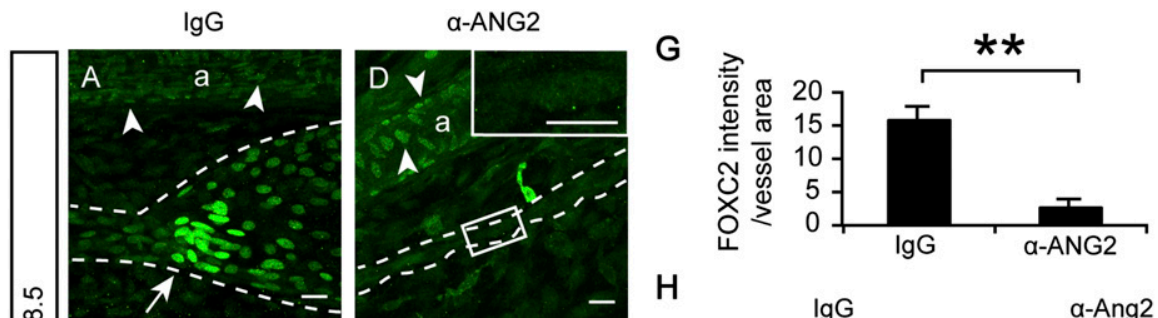

ஸे
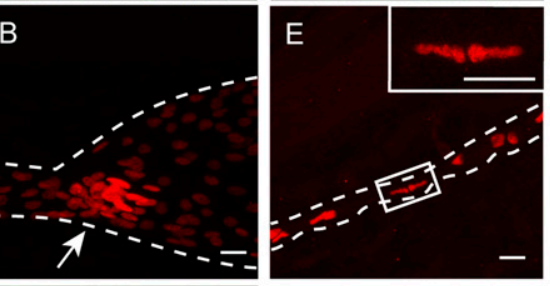

$\mathrm{H}$

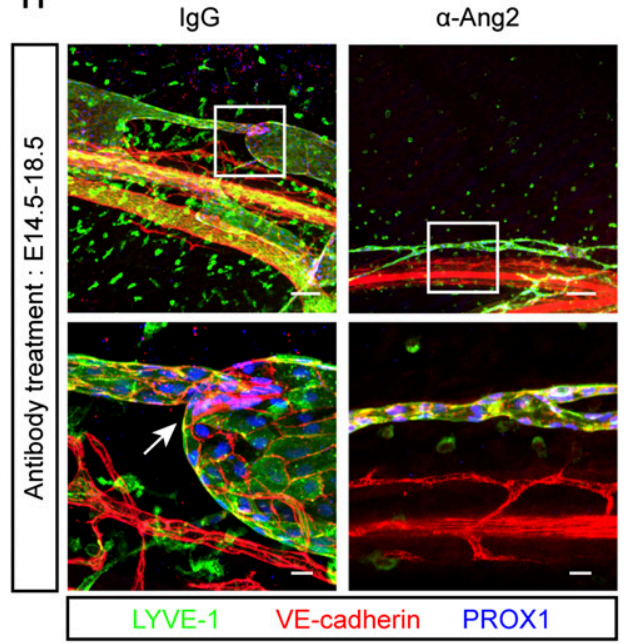

PROX1
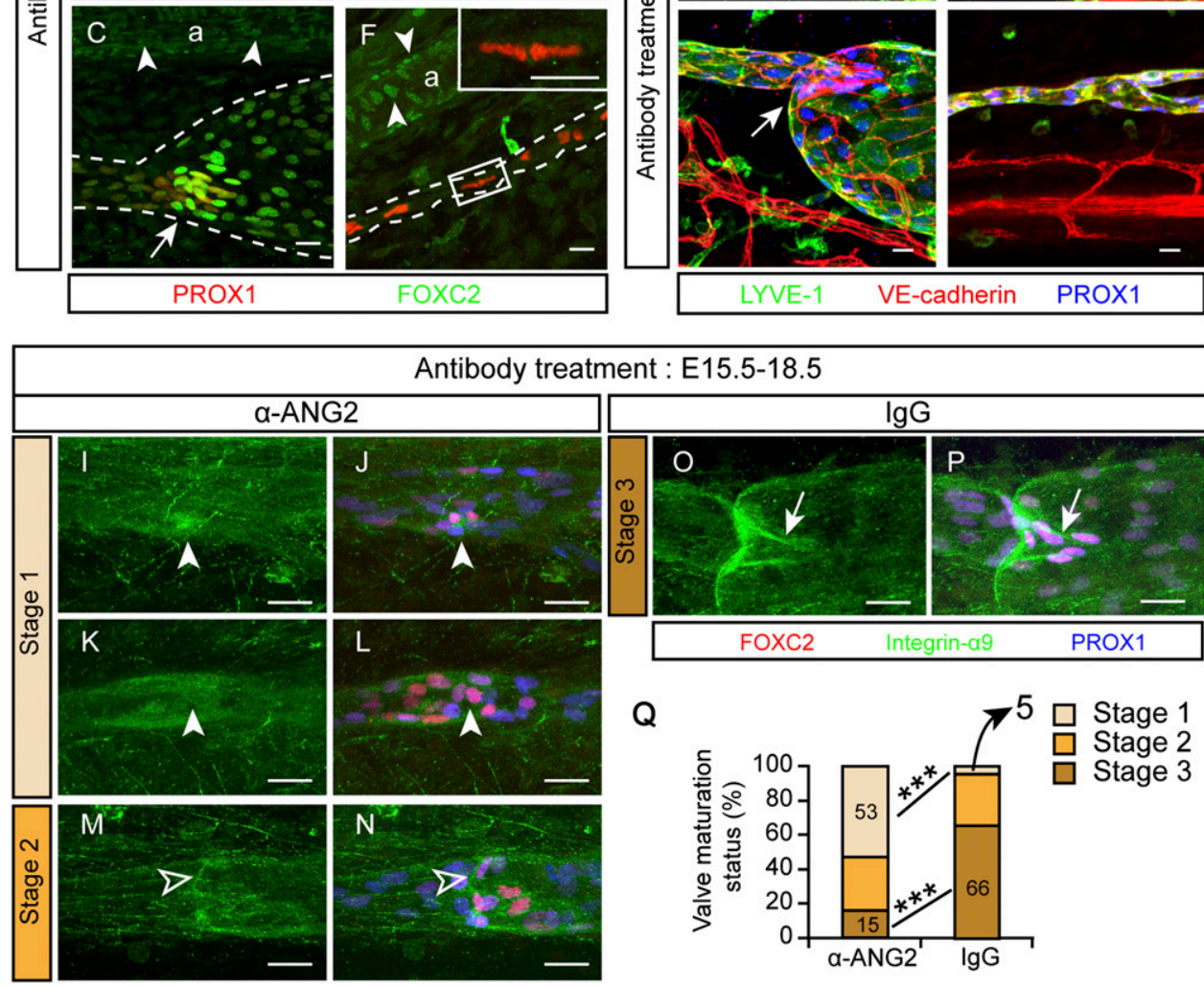

Q

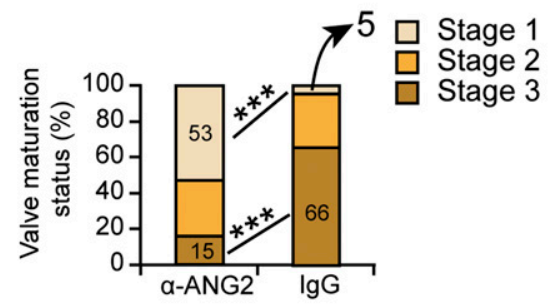

Figure 7. ANG2 regulates various steps of valve morphogenesis. $(A-F)$ Pregnant mice were treated with the indicated antibodies every other day starting at E12.5, and the mesenteries were analyzed at E18.5. $N=3-4$. (Arrows) Valves; (arrowheads) FOXC2 ${ }^{+}$ECs in the arteries. Lymphatic vessels are outlined by dashed lines (a). Boxed regions are magnified in the corresponding insets. Bars, $20 \mu \mathrm{m}$. $(G)$ Quantification of $A-F$. Mean \pm SEM. $\left(^{\star \star}\right) P<0.01$. $(H)$ Pregnant mice were treated with the indicated antibodies from E14.5 to E18.5. Bars: top panel, $100 \mu \mathrm{m}$; bottom panel, $20 \mu \mathrm{m}$. Boxed regions are magnified below. (Arrow) Valve. Bars: top panel, $100 \mu \mathrm{m}$; bottom panel, $20 \mu \mathrm{m}$. (I-P) Pregnant mice were treated with the indicated antibodies from E15.5 to E18.5. (Arrowheads) Clusters of lymphatic valveforming cells that failed to reorientate, express integrin- $\alpha 9$, and form valve leaflets; (open arrowheads) "ring-shaped" valves that expressed integrin- $\alpha 9$ but did not elongate leaflets; (arrows) mature valves with elongated leaflets. (Q) Evaluation and quantification of valve maturation in $I-P$. Thirty-two to 44 valves were analyzed from three to four embryos of each antibody treatment. $\left(^{\star \star \star}\right) P<0.001$.

almost two decades. Little progress has been made in terms of its role in lymphangiogenesis during the past 7 years. In this study, we uncovered a novel function of ANG2 in the patterning of specialized lymphatic endothelial cell-cell junctions. In addition, ANG2 is required for initiation of lymphatic valve formation and their subsequent maturation and ensures appropriate SMC recruitment to lymphatic vessels.
ANG2 has been suggested to act as a lymphangiogenic factor, as its gene deletion leads to lymphatic hypoplasia in mice (Gale et al. 2002; Dellinger et al. 2008). In agreement with this view, we found that the ANG2-blocking antibody interfered with lymphatic vessel sprouting and LEC proliferation. The gain-of-function approach that we used in this study further corroborated the lymphangiogenic 
role of Ang2. The lymphangiogenic activity seems to partially overlap with that of VEGF-C, as ANG2 overexpression rescued the decreased LEC proliferation but not the reduced vessel sprouting/branching that resulted from VEGFR3 blockade. In addition, the lymphangiogenic role of ANG2 contrasts with its context-dependent roles in angiogenesis. ANG2 has been shown to induce EC proliferation in the presence of high VEGF but apoptosis of ECs and vessel regression when VEGF is absent (Holash et al. 1999; Lobov et al. 2002). This analogy does not seem to apply to ANG2 and VEGF-C in lymphangiogenesis, as ANG2 overexpression did not exacerbate but partially rescued the reduced lymphangiogenesis induced by VEGFR-3 blockade. It remains to be defined by which mechanism ANG2 exerts its lymphangiogenic function during development.

A key finding of this study is that ANG2 is essential for the transformation of zipper-like junctions into a buttonlike pattern in initial lymphatics. This transformation is functionally important, as the button pattern allows an easy fluid drainage and leukocyte entry from surrounding tissues through the openings of endothelial flaps without the need to frequently open and close the adherens junctions (Baluk et al. 2007). Thus, it is likely that impaired button formation in initial lymphatics underlies, at least in part, the edema, swelling, and compromised fluid-draining capacity observed in anti-ANG2-treated and Ang2-l- mice by us and others (Dellinger et al. 2008).

Concomitantly with the failed transformation into buttons, phosphorylation of VE-cadherin Y685 was also inhibited by ANG2 blockade. Phosphorylation of this site has been linked to destabilization of the cell-cell junctions in blood vessels (Wallez et al. 2006; Dejana et al. 2008; Vestweber et al. 2009). Given that this phosphorylation is required for VE-cadherin internalization and degradation in response to vessel-permeabilizing agents (Orsenigo et al. 2012), it is possible that in lymphatic vessels, the ANG2dependent phosphorylation of VE-cadherin contributes to the dynamic change of the junctional patterns. However, a causal link between the phosphorylation and the transformation of VE-cadherin remains to be determined.

Another important finding of our study is that ANG2 also regulates LEC junctions in collecting lymphatics by maintaining junctional integrity. Chylous ascites has been reported in Ang2 $2^{-/-}$pups (Gale et al. 2002; Dellinger et al. 2008) and was also observed in the blocking antibodytreated neonatal mice in this study. Since zipper-like adherens junctions in collecting lymphatics ensure that lymph fluid within the vessel lumen does not leak out (Baluk et al. 2007), it is likely that the disrupted junctions upon ANG2 blockade or gene deletion contribute to the observed chylous ascites and leakage. The collecting lymphatics of $A n g 2^{-1-}$ mice are found to exhibit an oak leaf cell shape, which is characteristic of the LECs in initial lymphatics (Dellinger et al. 2008). Notably, the regulation of junctional integrity in collecting lymphatics seems to be a distinct function of ANG2, as conditional deletion of $V e g f c$ did not alter the junctions in collecting lymphatics (H Nurmi, P Saharinen, W Zheng, and K Alitalo, unpubl.). These results indicate that ANG2 has more specific functions than being just a general growth factor for cell proliferation and migration.

Although ANG2 has been implicated in blood vascular leakage in a number of disease models (van der Heijden et al. 2009; Huang et al. 2010), little evidence has directly attributed the blood vessel leakage to junctional failure. We did not detect changes of the phosphorylation or the pattern of VE-cadherin in blood vessels during development. Instead, our results indicate a prominent regulatory role for ANG2 in the EC junctions in developing lymphatic vessels.

The sensitivity of LEC junctions to ANG2 blockade was dependent on the developmental phase. In postnatal mice, when zippers had largely transformed to button junctions, the anti-ANG2 treatment could no longer revert them. In adult mice, the sensitivity was further decreased, and no apparent phenotypes were observed upon antiANG2 treatment for $6 \mathrm{~d}$ (data not shown). For comparison, mice appeared normal also when VEGF was blocked 4 wk after birth (Gerber et al. 1999) or when Ang1 was deleted after E13.5 (Jeansson et al. 2011). However, we cannot exclude the possibility that ANG2 contributes to lymphatic vessel function in pathological conditions in adult mice, as has been reported for ANG1 in response to injuries (Jeansson et al. 2011; Lee et al. 2013).

Lymphatic valves are absent from the Ang2 ${ }^{-/-}$neonatal mice (Dellinger et al. 2008). Our results advance the understanding of this defect by showing that ANG2 is necessary for the formation and maturation of valves but not their maintenance. Recent studies have uncovered a number of valve-regulating genes, including Foxc2 and Prox1 (Schulte-Merker et al. 2011). However, ANG2 did not seem to initiate valve formation directly via regulation of FOXC2. Instead, ANG2-dependent valve formation was required to maintain FOXC2 expression in the forming valves. Otherwise, FOXC2 expression was globally turned down throughout collecting lymphatics, possibly via the same intrinsic mechanisms that down-regulate FOXC2 expression in lymphangions. Furthermore, PROX1, which is down-regulated in wild-type lymphangions at E18.5, was uniformly and highly expressed throughout the collecting lymphatics. The lack of PROX1 down-regulation may impair the selection of valve-forming cells. Furthermore, the impaired lymphatic drainage in the skin suggests decreased lymph flow in the collecting lymphatics, particularly when these collecting lymphatics did not seem to have functional lumens at E18.5. Since recirculating lymph flow has been suggested to induce valve formation (Sabine et al. 2012), the lack of lymph flow might indirectly contribute to the observed valve agenesis.

Taken together, our data suggest that ANG2 has a previously unappreciated role in the formation of specialized LEC subsets (Supplemental Fig. S8). Without ANG2, the LECs exhibit a mixture of phenotypes. In initial lymphatics, LECs failed to acquire some typical features, such as the button pattern of LEC junctions, but ectopically recruit SMCs. In prospective lymphangions, on the other hand, the LECs failed to down-regulate LYVE1 and PROX1 while losing intact zipper-like junctions and SMC association. Moreover, insufficient numbers of LECs were activated to form valves. This mixed phenotype 
model also explains why the impaired button formation in initial lymphatics was partially restored in adult mice, whereas zippers in the collecting lymphatics were disrupted. In this regard, ANG2 seems to have a different role than the Notch pathway, which preferentially specifies cell fates in lymphangiogenesis (Zheng et al. 2011). It remains to be identified in future work whether LECs themselves are the only cellular source of ANG2, how ANG2 expression is distributed in lymphatic vessels, why ANG2 loss of function has more prominent effects on lymphatic vessels than on blood vessels during development, how ANG2 exerts its multiple functions, and how its activity is modulated by other regulators.

In conclusion, ANG2 is essential for appropriate patterning of LEC junctions at distinct compartments of a lymphatic vessel. Formation of buttons in initial lymphatics and maintenance of zippers in collecting lymphatics are functionally important, as they provide efficient fluid uptake by permeable initial lymphatics and delivery by nonleaky collecting lymphatics. While previous research has focused on the acquisition of valves to evaluate lymphatic vessel maturation, our results add another parameter by analyzing the junctional transformation in initial lymphatics. Knowledge of the effects of ANG2 on the function of the lymphatic drainage is important for therapeutic use of ANG2 antagonists in cancer and possibly in sepsis. Our findings should also provide a new basis for studies of other molecules involved in the process of junctional patterning as well as mechanisms that select for LECs that form different anatomic structures.

\section{Materials and methods}

\section{Transgenic and knockout animals}

The VE-cadherin-tTA (TET-Off) driver mice where generously provided by Dr. Laura Benjamin (Sun et al. 2005). The TetOAng2 responder has been previously described in detail (Holopainen et al. 2012b) and was backcrossed to C57Bl/6J for at least seven generations in this study. The driver and responder transgenic mouse lines were crossed to obtain DTG VE-cadherin;TetO-Ang2 offspring. Ang2 expression in DTG embryos was repressed by 2 $\mathrm{mg} / \mathrm{mL}$ tetracycline (Sigma-Aldrich) in 5\% sucrose in the drinking water for the pregnant females, starting within $2 \mathrm{~d}$ post-coitum, until Ang2 expression was induced by discontinuing tetracycline administration. The tetracycline-containing water was changed every $2-3 \mathrm{~d}$. Single transgenic or wild-type littermates were used as controls for DTG mice or embryos. Ang2 $2^{-1-}$ mice were bred as previously reported (Gale et al. 2002; Fiedler et al. 2006). Eightweek-old male mice or P5 pups were analyzed for their LEC junctions. The $P d g f b$-Cre-EGFP mice have been previously described (Claxton et al. 2008). PDGFB was visualized by staining for EGFP. The embryonic time points were determined according to vaginal plugs. The Committee for Animal Experiments of the District of Southern Finland approved all animal experiments.

\section{Antibody inhibition to study developing lymphatic vessels}

For the study of embryos, pregnant C57Bl/6J females were injected intraperitoneally (i.p.) with the ANG2-blocking antibody (Mazzieri et al. 2011; Leow et al. 2012), the anti-VEGFR3 antibody (Pytowski et al. 2005), or human immunoglobulin G (SigmaAldrich) as a control every other day at $30 \mathrm{mg} / \mathrm{kg}$ for the time periods indicated in the figure legends. For the study of neonatal mice, pups of NMRI background were injected subcutaneously in the back with $30 \mathrm{mg} / \mathrm{kg}$ anti-ANG2 or hIgG every other day starting at P0 and were analyzed at P5. Dexamethasone $(1 \mathrm{mg} / \mathrm{kg}$; Sigma-Aldrich, \#D2915) was injected i.p. into pregnant mice daily starting from E12.5 until E18.5 in combination with the anti-Ang2 antibody or hIgG, which were injected at E12.5, E14.5, and E16.5.

\section{Lymphangiography}

In embryos, $1-2 \mu \mathrm{L}$ of $10 \mathrm{mg} / \mathrm{mL}$ FITC-Dextran (2000 kD; SigmaAldrich) was injected into the periorbital dermis or the forelimb footpads at E19.5 (Sabine et al. 2012). One minute after the injection, the embryos were imaged for 10-15 min with a stereomicroscope (Leica, M205FA). Embryo viability was monitored by observing fetal breathing movements (12 of 14 for the control and 11 of 12 of anti-Ang2 antibody treatments).

In adult mice, $5 \mu \mathrm{L}$ of $25 \%$ FITC-Dextran $(2,000,000 \mathrm{kDa}$; Sigma) was injected intradermally into the ear rim, and the central region of the ear was imaged immediately using the Olympus IX81 inverted microscope. Alternatively, $40 \mu \mathrm{L}$ of $2 \%$ Evans Blue (in PBS) was injected into the right hindlimb footpad. After $30 \mathrm{~min}$, the mice were euthanized, Evans Blue content was ana-lyzed from $500 \mu \mathrm{L}$ of venous blood, and the injected footpad was extracted in formamide for $48 \mathrm{~h}$ at $56^{\circ} \mathrm{C}$. The optical intensity of the dye was measured at $620 \mathrm{~nm}$ with a spectrophotometer.

\section{Immunofluorescent staining and microscopy}

For whole-mount staining, tissues were fixed with $1 \%$ PFA for $1 \mathrm{~h}$ at room temperature. Subsequently, the tissues were washed with PBS, blocked with the Donkey Immunomix blocking buffer $15 \%$ donkey serum, $0.2 \%$ bovine serum albumin, $0.05 \%$ sodium azide, $0.3 \%$ Triton X-100 in PBS) for 30 min and incubated with primary antibodies diluted in the blocking buffer overnight at room temperature or for $2-3 \mathrm{~d}$ at $+4^{\circ} \mathrm{C}$. The primary antibodies were detected with appropriate secondary antibodies conjugated with Alexa fluorochromes (Invitrogen) with overnight incubation at room temperature. The samples were then mounted in mounting medium containing DAPI (Vector Laboratories). Frozen sections of the ventral skin $(10 \mu \mathrm{m})$ were cut and stained as previously described (Holopainen et al. 2012a).

The following primary antibodies were used: FOXC2 (1:2500) (Furumoto et al. 1999), GFP (1:1500; Torrey Pines Biolabs, \#TP401), integrin- $\alpha 9$ (1:500; R\&D Systems, \#AF3827), Ki67 (1:200; Abcam, \#ab16667), LYVE1 (1:2000) (Petrova et al. 2004), 2-3 $\mu \mathrm{g} / \mathrm{mL}$ PROX1 (1:500; R\&D Systems, \#AF2727) (Karkkainen et al. 2004), SMA (1:500; Sigma-Aldrich, \#6198), VE-cadherin (1:100 [BD Biosciences, \#555289] and 1:100 [eBioscience, \#141441]), VE-cadherin P-Y685 (Orsenigo et al. 2012), and VEGFR3 (1:50; R\&D Systems, \#AF743).

All whole-mount-stained samples were imaged using a confocal microscope (Zeiss LSM 780, $\times 10$ : air objectives with numerical aperture $[\mathrm{NA}]=0.45 ; \times 40$ : oil objective with NA $=1.30$ ). Threedimensional projections were digitally reconstructed from Zstacks with the LSM Zen software (Carl Zeiss). Some images were stitched from tile-scanned images using the Zen program. The brightness and contrast of the images were adjusted using Adobe Photoshop CS5 (Adobe) in accordance with general guidelines for scientific image processing.

\section{Quantitative and statistical analyses}

Vessel area and length were analyzed using ImageJ (National Institutes of Health). VE-cadherin P-Y $685^{+}$pixels out of total VEcadherin $^{+}$pixels within lymphatic vessels were quantified using 
the Image Calculator and the ROI Manager of ImageJ. Analysis of FOXC2 and SMA levels in lymphatic vessels were analyzed similarly. The number of vessel branch points, sprouts, cells per vessel length, and $\mathrm{Ki} 67^{+}$LECs were counted manually. For quantification of migration, a square of $1400 \mu \mathrm{m} \times 800 \mu \mathrm{m}$, with its longitudinal axis aligned to the ventral midline, was drawn as indicated in the figures, and the number of vessels within the square was counted. Zipper junctions were defined as continuous junctions at cell-cell borders, accompanied by elongated cell shapes; transforming junctions were defined as discontinuous junctions that align with cell-cell borders, accompanied by elongated cell shapes; and buttons were defined as discontinuous junctions that are not parallel to cell-cell borders and are associated with an oak leaf cell shape (Baluk et al. 2007). Disrupted junctions were defined as junctions with a jagged shape and breaks in continuity, associated with a less elongated, but not an oak leaf, cell shape.

The majority of experiments were repeated two to five times as indicated in the figure legends with consistent results. A few experiments were performed once, with $N \geq 3$ per group. For comparison of means, data were pooled from independently performed repetitive experiments, were analyzed using a two-way ANOVA without interaction, and are presented as mean \pm standard error of mean (SEM). Fisher's exact test was used to compare proportions. Holm-Sidak test was used as a post hoc analysis when more than two groups were compared. Statistical analyses were carried out with SPSS Statistics (version 20.0) or manually. Statistical significance is indicated in the figures as follows: $P<0.05\left(^{\star}\right)$, $P<0.01\left(^{\star \star}\right), P<0.001\left(^{\star \star \star}\right)$, and not significant (N.S.).

\section{Competing interest statement}

ChingChing Leow is an employee of MedImmune.

\section{Acknowledgments}

We thank Dr. Li-Chin Yao for helpful discussion on VE-cadherin staining; Dr. Laura Benjamin for the VE-cadherin-tTA mice; Dr. Taija Mäkinen for the $P d g f b$-Cre-EGFP mice; Aleksanteri Aspelund for help in some experiments; Jarmo Koponen, Kirsi Lintula, and Tapio Tainola for expert technical assistance; the Biomedicum Imaging Unit for microscopy support; and the staff at Haartman Institute and Biomedicum Animal Facilities for excellent animal husbandry. The Academy of Finland, the European Research Council (ERC-2010-AdG-268804), the Leducq Foundation (11CVD03), and the Marie Curie Vessel network of the European Union are acknowledged for funding. This work was supported by personal grants (to W.Z.) from Biomedicum Helsinki Foundation, Orion-Farmos Research Foundation, and Clinical Chemistry Research Foundation.

\section{References}

Alitalo K. 2011. The lymphatic vasculature in disease. Nat Med 17: $1371-1380$.

Augustin HG, Koh GY, Thurston G, Alitalo K. 2009. Control of vascular morphogenesis and homeostasis through the angiopoietin-Tie system. Nat Rev Mol Cell Biol 10: 165-177.

Baluk P, Fuxe J, Hashizume H, Romano T, Lashnits E, Butz S, Vestweber D, Corada M, Molendini C, Dejana E, et al. 2007. Functionally specialized junctions between endothelial cells of lymphatic vessels. J Exp Med 204: 2349-2362.

Bazigou E, Xie S, Chen C, Weston A, Miura N, Sorokin L, Adams R, Muro AF, Sheppard D, Mäkinen T. 2009. Integrin- $\alpha 9$ is required for fibronectin matrix assembly during lymphatic valve morphogenesis. Dev Cell 17: 175-186.
Betsholtz C. 2004. Insight into the physiological functions of PDGF through genetic studies in mice. Cytokine Growth Factor Rev 15: 215-228.

Claxton S, Kostourou V, Jadeja S, Chambon P, Hodivala-Dilke K, Fruttiger M. 2008. Efficient, inducible Cre-recombinase activation in vascular endothelium. Genesis 46: 74-80.

Dejana E, Orsenigo F, Molendini C, Baluk P, McDonald DM. 2008. Organization and signaling of endothelial cell-to-cell junctions in various regions of the blood and lymphatic vascular trees. Cell Tissue Res 335: 17-25.

Dellinger M, Hunter R, Bernas M, Gale N, Yancopoulos G, Erickson R, Witte M. 2008. Defective remodeling and maturation of the lymphatic vasculature in Angiopoietin-2 deficient mice. Dev Biol 319: 309-320.

Dumont DJ, Gradwohl G, Fong GH, Puri MC, Gertsenstein M, Auerbach A, Breitman ML. 1994. Dominant-negative and targeted null mutations in the endothelial receptor tyrosine kinase, tek, reveal a critical role in vasculogenesis of the embryo. Genes Dev 8: 1897-1909.

Fiedler U, Reiss Y, Scharpfenecker M, Grunow V, Koidl S, Thurston G, Gale NW, Witzenrath M, Rosseau S, Suttorp N, et al. 2006. Angiopoietin-2 sensitizes endothelial cells to TNF- $\alpha$ and has a crucial role in the induction of inflammation. Nat Med 12: 235-239.

Furumoto TA, Miura N, Akasaka T, Mizutani-Koseki Y, Sudo H, Fukuda K, Maekawa M, Yuasa S, Fu Y, Moriya H, et al. 1999. Notochord-dependent expression of MFH1 and PAX1 cooperates to maintain the proliferation of sclerotome cells during the vertebral column development. Dev Biol 210: 15-29.

Gale NW, Thurston G, Hackett SF, Renard R, Wang Q, McClain J, Martin C, Witte C, Witte MH, Jackson D, et al. 2002. Angiopoietin-2 is required for postnatal angiogenesis and lymphatic patterning, and only the latter role is rescued by Angiopoietin-1. Dev Cell 3: 411-423.

Gerber HP, Hillan KJ, Ryan AM, Kowalski J, Keller GA, Rangell L, Wright BD, Radtke F, Aguet M, Ferrara N. 1999. VEGF is required for growth and survival in neonatal mice. Development 126: 1149-1159.

Holash J, Maisonpierre PC, Compton D, Boland P, Alexander CR, Zagzag D, Yancopoulos GD, Wiegand SJ. 1999. Vessel cooption, regression, and growth in tumors mediated by angiopoietins and VEGF. Science 284: 1994-1998.

Holopainen T, López-Alpuche V, Zheng W, Heljasvaara R, Jones D, He Y, Tvorogov D, D'Amico G, Wiener Z, Andersson LC, et al. 2012a. Deletion of the endothelial Bmx tyrosine kinase decreases tumor angiogenesis and growth. Cancer Res 72: 35123521.

Holopainen T, Saharinen P, D'Amico G, Lampinen A, Eklund L, Sormunen R, Anisimov A, Zarkada G, Lohela M, Heloterä H, et al. 2012b. Effects of angiopoietin-2-blocking antibody on endothelial cell-cell junctions and lung metastasis. I Natl Cancer Inst 104: 461-475.

Huang H, Bhat A, Woodnutt G, Lappe R. 2010. Targeting the ANGPT-TIE2 pathway in malignancy. Nat Rev Cancer 10: 575-585.

Jeansson M, Gawlik A, Anderson G, Li C, Kerjaschki D, Henkelman M, Quaggin SE. 2011. Angiopoietin-1 is essential in mouse vasculature during development and in response to injury. J Clin Invest 121: 2278-2289.

Karkkainen MJ, Haiko P, Sainio K, Partanen J, Taipale J, Petrova TV, Jeltsch M, Jackson DG, Talikka M, Rauvala H, et al. 2004. Vascular endothelial growth factor $\mathrm{C}$ is required for sprouting of the first lymphatic vessels from embryonic veins. Nat Immunol 5: 74-80.

Koltowska K, Betterman KL, Harvey NL, Hogan BM. 2013. Getting out and about: the emergence and morphogenesis of 
the vertebrate lymphatic vasculature. Development 140: 1857-1870.

Lee J, Kim KE, Choi DK, Jang JY, Jung J-J, Kiyonari H, Shioi G, Chang W, Suda T, Mochizuki N, et al. 2013. Angiopoietin-1 guides directional angiogenesis through integrin $\alpha \mathrm{v} \beta 5$ signaling for recovery of ischemic retinopathy. Sci Transl Med 5: 203ra127.

Leow CC, Coffman K, Inigo I, Breen S, Czapiga M, Soukharev S, Gingles N, Peterson N, Fazenbaker C, Woods R, et al. 2012. MEDI3617, a human anti-angiopoietin 2 monoclonal antibody, inhibits angiogenesis and tumor growth in human tumor xenograft models. Int J Oncol 40: 1321-1330.

Lobov IB, Brooks PC, Lang RA. 2002. Angiopoietin-2 displays VEGF-dependent modulation of capillary structure and endothelial cell survival in vivo. Proc Natl Acad Sci 99: 11205-11210.

Maisonpierre PC. 1997. Angiopoietin-2, a natural antagonist for Tie2 that disrupts in vivo angiogenesis. Science 277: 55-60.

Mazzieri R, Pucci F, Moi D, Zonari E, Ranghetti A, Berti A, Politi LS, Gentner B, Brown JL, Naldini L, et al. 2011. Targeting the ANG2/TIE2 axis inhibits tumor growth and metastasis by impairing angiogenesis and disabling rebounds of proangiogenic myeloid cells. Cancer Cell 19: 512-526.

Norrmén C, Ivanov KI, Cheng J, Zangger N, Delorenzi M, Jaquet $M$, Miura N, Puolakkainen P, Horsley V, Hu J, et al. 2009. FOXC2 controls formation and maturation of lymphatic collecting vessels through cooperation with NFATc1. J Cell Biol 185: 439-457.

Orsenigo F, Giampietro C, Ferrari A, Corada M, Galaup A, Sigismund S, Ristagno G, Maddaluno L, Koh GY, Franco D, et al. 2012. Phosphorylation of VE-cadherin is modulated by haemodynamic forces and contributes to the regulation of vascular permeability in vivo. Nat Commun 3: 1208.

Patan S. 1998. TIE1 and TIE2 receptor tyrosine kinases inversely regulate embryonic angiogenesis by the mechanism of intussusceptive microvascular growth. Microvasc Res 56: 1-21.

Petrova TV, Karpanen T, Norrmén C, Mellor R, Tamakoshi T, Finegold D, Ferrell R, Kerjaschki D, Mortimer P, YlaHerttuala S, et al. 2004. Defective valves and abnormal mural cell recruitment underlie lymphatic vascular failure in lymphedema distichiasis. Nat Med 10: 974-981.

Pytowski B, Goldman J, Persaud K, Wu Y, Witte L, Hicklin DJ, Skobe M, Boardman KC, Swartz MA. 2005. Complete and specific inhibition of adult lymphatic regeneration by a novel VEGFR-3 neutralizing antibody. J Nat1 Cancer Inst 97: 14-21.

Sabine A, Agalarov Y, Maby-El Hajjami H, Jaquet M, Hägerling R, Pollmann C, Bebber D, Pfenniger A, Miura N, Dormond O. 2012. Mechanotransduction, PROX1, and FOXC2 cooperate to control connexin 37 and calcineurin during lymphatic-valve formation. Dev Cell 22: 430-445.

Sato TN, Tozawa Y, Deutsch U, Wolburg-Buchholz K, Fujiwara Y, Gendron-Maguire M, Gridley T, Wolburg H, Risau W, Qin Y. 1995. Distinct roles of the receptor tyrosine kinases Tie-1 and Tie-2 in blood vessel formation. Nature 376: 70-74.

Schulte-Merker S, Sabine A, Petrova TV. 2011. Lymphatic vascular morphogenesis in development, physiology, and disease. J Cell Biol 193: 607-618.

Sun JF, Phung T, Shiojima I, Felske T, Upalakalin JN, Feng D, Kornaga T, Dor T, Dvorak AM, Walsh K. 2005. Microvascular patterning is controlled by fine-tuning the Akt signal. Proc Natl Acad Sci 102: 128-133.

Suri C, Jones PF, Patan S, Bartunkova S, Maisonpierre PC, Davis S, Sato TN, Yancopoulos GD. 1996. Requisite role of angiopoietin-1, a ligand for the TIE2 receptor, during embryonic angiogenesis. Cell 87: 1171-1180.

Tammela T, Alitalo K. 2010. Lymphangiogenesis: molecular mechanisms and future promise. Cell 140: 460-476.

van der Heijden M, van Nieuw Amerongen GP, Chedamni S, van Hinsbergh VWM, Johan Groeneveld AB. 2009. The
angiopoietin-Tie 2 system as a therapeutic target in sepsis and acute lung injury. Expert Opin Ther Targets 13: 39-53.

Vestweber D, Winderlich M, Cagna G, Nottebaum AF. 2009. Cell adhesion dynamics at endothelial junctions: VE-cadherin as a major player. Trends Cell Biol 19: 8-15.

Wallez Y, Cand F, Cruzalegui F, Wernstedt C, Souchelnytskyi S, Vilgrain I, Huber P. 2006. Src kinase phosphorylates vascular endothelial-cadherin in response to vascular endothelial growth factor: identification of tyrosine 685 as the unique target site. Oncogene 26: 1067-1077.

Wigle JT, Oliver G. 1999. Prox1 function is required for the development of the murine lymphatic system. Cell 98: 769-778.

Yang Y, Oliver G. 2014. Development of the mammalian lymphatic vasculature. J Clin Invest 124: 888-897.

Yao LC, Baluk P, Srinivasan RS, Oliver G, McDonald DM. 2012. Plasticity of button-like junctions in the endothelium of airway lymphatics in development and inflammation. Am J Pathol 180: 2561-2575.

Zheng W, Tammela T, Yamamoto M, Anisimov A, Holopainen T, Kaijalainen S, Karpanen T, Lehti K, Yla-Herttuala S, Alitalo K. 2011. Notch restricts lymphatic vessel sprouting induced by vascular endothelial growth factor. Blood 118: 1154-1162.

Zheng W, Aspelund A, Alitalo K. 2014. Lymphangiogenic factors, mechanisms, and applications. J Clin Invest 124: 878-887.

Ziegler T, Horstkotte J, Schwab C, Pfetsch V, Weinmann K, Dietzel S, Rohwedder I, Hinkel R, Gross L, Lee S, et al. 2013. Angiopoietin 2 mediates microvascular and hemodynamic alterations in sepsis. J Clin Invest 123: 3436-3445. 


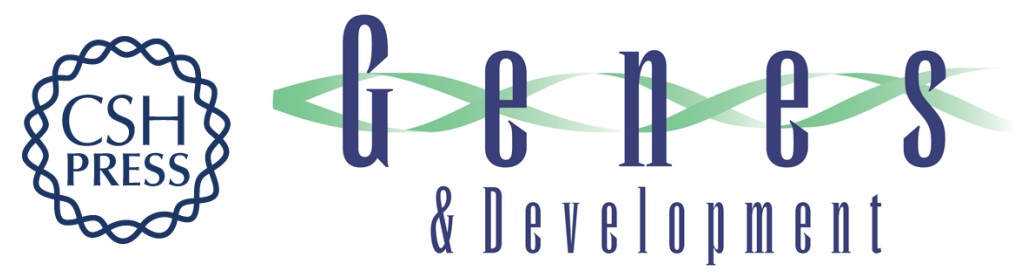

\section{Angiopoietin 2 regulates the transformation and integrity of lymphatic endothelial cell junctions}

Wei Zheng, Harri Nurmi, Sila Appak, et al.

Genes Dev. 2014, 28:

Access the most recent version at doi:10.1101/gad.237677.114

Supplemental
Material http://genesdev.cshlp.org/content/suppl/2014/07/16/28.14.1592.DC1

References This article cites 45 articles, 12 of which can be accessed free at:

http://genesdev.cshlp.org/content/28/14/1592.full.html\#ref-list-1

Creative This article is distributed exclusively by Cold Spring Harbor Laboratory Press for the first

Commons

License

Email Alerting

Service six months after the full-issue publication date (see

http://genesdev.cshlp.org/site/misc/terms.xhtml). After six months, it is available under a Creative Commons License (Attribution-NonCommercial 4.0 International), as described at http://creativecommons.org/licenses/by-nc/4.0/.

Receive free email alerts when new articles cite this article - sign up in the box at the top right corner of the article or click here.

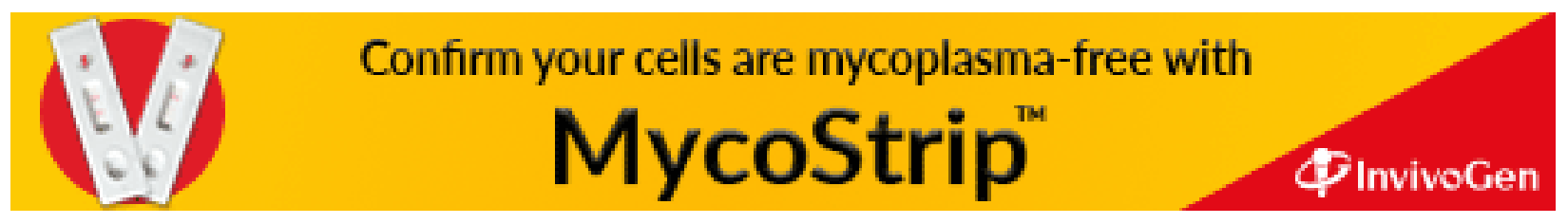

